\title{
ESTRATÉGIAS DE DIFERENCIAÇÃO: UM ESTUDO EM RESTAURANTES DE UMA CIDADE HISTÓRICA

Lucas Lima Marques ${ }^{1}$

Felipe Gouvêa Pena ${ }^{2}$

Simone Aparecida Simões Rocha

\footnotetext{
${ }^{1}$ Universidade Federal de Ouro Preto

${ }^{2}$ Centro Universitário de Belo Horizonte
} 


\section{ESTRATÉGIAS DE DIFERENCIAÇÃO: UM ESTUDO EM RESTAURANTES DE UMA CIDADE HISTÓRICA}

\section{Resumo:}

As organizações contemporâneas enfrentam um ambiente altamente competitivo na busca por parcelas de mercado. Nesses termos, os gestores ficam obrigados a traçar diferenciais para os seus negócios, visando uma posição sustentável da empresa. O objetivo do trabalho foi analisar as estratégias de diferenciação adotadas por um grupo de restaurantes do centro histórico de uma cidade do interior de Minas Gerais. Utilizou-se uma abordagem qualitativa de caráter descritivo e exploratório sendo realizadas entrevistas com gestores/proprietários de quatro restaurantes do centro histórico da cidade. Os resultados indicam que todos os comerciantes estão dispostos a ingressar em uma rede de compras com o intuito de reduzir seus custos e maximizar as oportunidades.

Palavras-chave: estratégias; diferenciação; restaurantes; gestores.

\section{$1 \quad$ Introdução}

Desde os anos 90, a concorrência ou competitividade entre as empresas, tornou-se cada vez mais comum, e dificilmente uma organização não enfrenta outra empresa que ofereça os mesmos serviços ou produtos que a mesma. Esta competição começou a ocorrer de forma mais frequente e comum após a globalização e os avanços tecnológicos, abrindo espaço e permitindo que empresas não somente regionais, mas de outros países pudessem competir dentro de um mesmo espaço (MOTTA, 1995).

A mundialização pode ser vista também, como uma forma das empresas trabalharem no processo produtivo impondo seus modelos de produção e busca por incentivos e benefícios para se sobressaírem perante seus concorrentes, criando barreiras que dificultem a entrada de novas empresas em seu ramo de atuação (GARCIA-PARPET, 2004).

Porém, essa competitividade trouxe implicações para os comerciantes em forma de competições desleais devido ao poder político, financeiro e tecnológico de determinadas empresas que competem com outras instituições menores pelo mesmo público, como também, abriu portas para que os gestores pudessem sair de sua zona de conforto para trazer novidades aos clientes. Desse modo, foi possível desenvolver novos produtos e serviços, melhorando a qualidade de atendimento, preço, e outras estratégias que possibilitassem torná-los mais competitivos, os clientes, por outro lado, puderam usufruir de melhorias na qualidade de serviço, maior variedade de opções, preços de produtos e desenvolvimento tecnológico, sendo cada produto ou tipo de serviço, escolhido de acordo com a necessidade e/ou gosto (CONTO; FEIL, 1997).

Diante destas transformações, as empresas tiveram de se reestruturar e se adaptar ao novo cenário competitivo para se manterem no mercado e aumentar sua produtividade. $\mathrm{O}$ governo por sua vez, também teve sua participação nesse modelo de concorrência, onde passou a exercer principalmente a função de desenvolver ferramentas para que suas empresas também se tornassem mais competitivas diante deste novo modelo de gestão global. Por conta dessas transformações e por se tratar de um assunto que cabe amplos tipos de opiniões ao se utilizar o termo competitividade, existem diversos pontos de vista na literatura referente ao significado 
do presente termo, no que tange desde indicadores de desempenho, eficiência e capacitação (NETO; PIZZOLATO, 2001).

No setor de restaurantes, esses impactos também puderam ser observados, Segundo Billig et al. (2016), devido às mudanças ocasionadas pelos avanços tecnológicos e sociais, a refeição em estabelecimentos alimentícios, passou a ser mais consumida e necessária para a sociedade, aumentando a competitividade em setores de alimentos, cabendo aos gestores destes estabelecimentos buscarem informações a respeito dos gostos de seus consumidores e a satisfação dos mesmos. Porém, isso acabou por gerar impactos em empreendimentos destes setores, onde os gestores devem estar sempre atentos as constantes mudanças da sociedade, e estarem sempre buscando rever suas estratégias adotadas para se manterem mais competitivos, se atentando principalmente na melhoria constante de seus produtos, redução de seus custos e a efetividade de seus processos operacionais. Nesses termos teve-se como objetivo de pesquisa: analisar as estratégias de diferenciação adotadas por um grupo de restaurantes do centro histórico de uma cidade do interior de Minas Gerais.

Como justificativas para a pesquisa pontua-se que ela pode trazer informações tanto para o meio acadêmico, como para o ramo empresarial e para a sociedade, de modo a contribuir com conhecimentos que podem ser utilizados por toda a população, acarretando um benefício mútuo para todos (CUNHA; VOGT; BIAVATTI, 2015).

No que tange o ramo empresarial, as informações contidas na pesquisa, podem auxiliar os comerciantes no ramo de restaurantes a compreender como se dão as interações entre empresas deste setor, que disputam espaço em uma cidade do interior de Minas Gerais, a observarem os meios utilizados para se diferenciarem e como as estratégias empregadas influenciam no gosto e na escolha do consumidor ao escolher o estabelecimento de sua preferência. Outro ponto da pesquisa seria aproximar a Universidade da Comunidade, mostrando para a sociedade que tal parceria pode gerar benefícios mútuos para ambos os seguimentos, onde o presente estudo poderá melhorar e desenvolver os comércios através das informações contidas no mesmo.

Através das informações contidas no estudo, será possível analisar a competitividade estratégica das empresas, que segundo HITT, IRELAND e HOSKISSON (2008) é definida como a implantação e formulação bem-sucedida de uma empresa na sua criação de valor. Os mesmos autores também definem estratégia como o conjunto incorporado e dirigido de estratégias e ações estabelecidas para analisar capacidades essenciais com o intuito de obter vantagem competitiva. Após a estratégia ser definida, a empresa escolherá meios e alternativas para competir no mercado, gerando vantagem competitiva, que é a forma como a empresa se diferenciará no mercado, implementando um produto ou serviço complexo ou inviável financeiramente para ser copiado ou reproduzido. Deste modo, a empresa poderá obter uma posição mais sustentável e competitiva no mercado, tornando possível analisar o comportamento competitivo (conjunto de ações tomados pela empresa para garantir e proteger sua posição sustentável no mercado) das empresas estudadas (HITT; IRELAND; HOSKISSON, 2008).

\section{Referencial Teórico}

O referencial teórico irá abordar temas que envolvem diretamente o setor de restaurantes, definindo e explicando os conceitos de competitividade e relações interorganizacionais. 


\subsection{Competitividade}

O mercado competitivo é o local onde as empresas competem entre si disputando parcelas de clientes com o intuito de se sobressaírem perante seus concorrentes através de produtos inovadores e/ou que atendam às necessidades de seus respectivos consumidores. Dentro deste contexto, as empresas buscam cada vez mais formas de se diferenciarem não só no aprimoramento e melhoria da qualidade de seus produtos, como também algumas utilizam como estratégia o desenvolvimento sustentável, desenvolvimento de tecnologias ou mecanismos que reaproveitem, diminuem ou que reduzem os impactos ambientais (LOMBARDI; BRITO, 2007).

Porém, este fator possibilitou que novos tipos de empresas, ideias ou serviços fossem criados para atender ou gerar novas necessidades nos consumidores, possibilitando a criação de novas empresas ou serviços, com o intuito de se tornarem cada vez mais competitivas e inovadoras. Para atender essas necessidades, muitas empresas passaram a investir em inteligência competitiva, onde a grande responsabilidade deste conceito é buscar novas formas, produtos e serviços para atrair os clientes.

Nesse contexto, pode-se citar o grande aumento do número de concorrentes, que são empresas que atuam no mesmo segmento, e competem com produtos semelhantes e normalmente, os mesmos tipos de clientes, gerando a rivalidade competitiva, entendida como o conjunto de medidas tomadas pelas empresas que são concorrentes para conseguirem um melhor posicionamento no mercado ou uma posição mais sustentável no mesmo (HITT; IRELAND; HOSKISSON, 2007).

A Inteligência Competitiva, é a junção de informações internas e externas referentes tanto aos clientes da corporação, como também de seus funcionários, para analisar possíveis soluções ou ferramentas para corrigir um problema ou melhorar um procedimento dentro da empresa diante do mercado, tornando mais assertivo as implementações adotadas. Este conceito trabalha a ideia de que os dados obtidos, são muito importantes para as tomadas de decisões das empresas, porém, só eles não são suficientes para que essas medidas ou estratégias criadas possam ser totalmente eficazes, portanto, é necessário que seja desenvolvida a Inteligência Competitiva, que é responsável por trabalhar com os fluxos formais e informais de informações dentro de uma organização para analisar não só as ideias que os gestores têm para os produtos, como também captar possíveis inovações que possam ser frutos das visões e percepções que os próprios funcionários tem da empresa e dos clientes. Portanto, uma boa implantação da inteligência competitiva, pode trazer diferentes tipos de inovações para uma empresa, desde a criação ou melhoria de um produto ou serviço, até mesmo a implantação correta de alguma estratégia empresarial baseada nos dados colhidos (VALENTIM et al., 2003).

O Serviço Brasileiro de Apoio às Micro e Pequenas Empresas (SEBRAE), também aponta a inteligência competitiva para micro e pequenas empresas como fundamental para o seu desenvolvimento, caracterizando a mesma como o meio de utilizar as informações do mercado de forma inteligente, para garantir a sobrevivência mesma em um ambiente muito competitivo. Para isso, é necessário que o empreendimento crie, utilize, compartilhe informações e conhecimento utilizando ferramentas de tecnologia da informação e da comunicação. Esse processo é denominado Inteligência Competitiva, sendo considerado como um processo de aprendizado determinado pela competitividade, possibilitando o 
desenvolvimento de estratégias competitivas de curto e longo prazo, através das informações obtidas (SEBRAE, 2016).

Outro fator que pode ser observado são as influências que os fatores externos exercem diretamente no mercado competitivo para as empresas, onde os mesmos podem influenciar diretamente no processo de gestão da mesma, nos públicos alvos, em seus preços, tipos de serviços prestados e estratégias de marketing voltadas para as necessidades daquela organização. Um bom planejamento estratégico e visão de mercado podem ser decisivos na hora de tomar essas decisões. A competitividade pode ser bem definida como a capacidade da empresa de desenvolver e executar estratégias de diferenciação, que lhe possibilitem desenvolver ou manter, de forma contínua, uma posição permanente no mercado. Desse modo é possível observar e analisar que as empresas em sua maioria, precisam sempre se renovar e reinventar para poderem continuar operando no mercado. Empresas que não se desenvolvem no mercado, dificilmente sobrevivem durante os anos (HAGUENAUER; FERRAZ; KUPFER, 1996).

Em relação a essas situações, é possível relacionar as 5 forças Porter que são: a) ameaça de novos entrantes (surgimento de novas empresas que competem entre si pela mesma fatia do mercado); b) ameaça de substitutos (produtos de concorrentes que são similares aos produzidos por uma indústria, mas que atendem as necessidades dos mesmos consumidores, e que podem diminuir o número de seus clientes); c) poder de negociação dos clientes (capacidade que os clientes possuem de diminuir os preços dos serviços prestados pela empresa responsável por fornecer aquele produto ou serviço); d) poder de negociação dos fornecedores (poder que os fornecedores têm ao vender o produto para seus compradores, podendo aumentar ou diminuir o preço, além de regular a quantidade fornecida. Dentro dessa situação, se encaixam os grandes fornecedores capazes de dominar o mercado neste segmento, e fornecedores de componentes ou serviços exclusivos, que somente eles ou poucos fornecedores produzem ou tem acesso); e e) rivalidade entre os concorrentes (empresas que competem pelos mesmos consumidores) (PORTER, 1985).

De acordo com Oliveira (2004) essas forças são responsáveis por determinar quais estratégias à empresa deverá tomar perante seus concorrentes e como a mesma atrairá seus clientes, porém além dessas forças, existem outras forças externas que são capazes de auxiliar ou prejudicar a empresa de acordo com o momento em que a mesma vive, sendo alguns destes fatores: políticos, financeiros, internacionais, econômicos, entre outros. Esses fatores podem comprometer determinados planejamentos estratégicos efetuados pela empresa, que deverá reorganizar sua estrutura e tomada de decisões após a ocorrência dos mesmos, sendo estes fatores, na maior parte dos casos, imprevisíveis ou de difícil previsão, podendo comprometer as vantagens competitivas desta instituição (OLIVEIRA, 2004).

A tecnologia e o acesso à informação são fundamentais para tornar-se uma empresa competitiva, onde a facilidade de se obter conhecimento em conjunto com os avanços tecnológicos, exige cada vez mais que os proprietários das empresas permaneçam atualizados a respeito das informações que acontecem no mundo e sempre busquem por inovar os seus produtos. $\mathrm{O}$ diferencial entre as empresas passou a ser o desenvolvimento de novos produtos e/ou serviços em curtos espaços de tempo, porém, esse processo de inovação exige que as empresas tenham acesso a ferramentas tecnológicas e novos maquinários, mas pelo cenário atual brasileiro isso surge com um grande problema para os micro e pequenos empreendedores, 
devido aos altos valores cobrados para se obter estes instrumentos que são cada vez mais importantes no processo de inovação dentro das empresas (ALVIM, 1998).

\subsection{Modelos de Diferenciação}

As diferenciações entre as firmas podem ser vistas tanto como um meio da corporação se diferenciar a ponto de compreender quais serão seus concorrentes, como o meio das mesmas dificultarem a inserção de outras companhias no mesmo ramo ao qual estão inseridas. Um fator determinante para avaliar se as estratégias estão no caminho correto e a inserção das mudanças no produto foram assertivas, está diretamente associado aos gastos feitos com propagandas e diferenciação, demonstrando sua dimensão na estrutura de mercado, onde a diferenciação de produtos estão relacionadas com as características básicas dos mesmos e as políticas e diferenciais presentes na empresa passadas através de suas propagandas (FIGUEIREDO, 1983).

Apesar de muitas empresas competirem no mesmo mercado através da venda dos mesmos produtos, ou semelhantes, elas se distinguem umas das outras através de seus níveis de eficiência, estrutura física e organizacional, forma de gestão, cultura organizacional, entre outras formas. Essas diferenças presentes entre as mesmas influenciam na sua capacidade de competir e nos clientes que são atraídos para as mesmas, onde pelo senário de grandes mudanças que as firmas sofrem, e se espera que elas a todo o momento diversifiquem seus produtos, acabam por impactar diretamente em seus produtos ofertados, e até mesmo em sua cultura (CROZATTI 1998).

Muitas empresas utilizam os sistemas de controle gerencial como ferramenta para gerar inovação e desenvolver o empreendedorismo, isto posto, cabe a empresa investir na área de pesquisa e desenvolvimento com o intuito de criar novos produtos, que terão como foco trazer uma posição mais sustentável para a empresa diante do mercado. Um dos pontos que requerem maior atenção por parte das empresas é a inovação, que pode ser obtida através de vários meios, principalmente pelo recolhimento de dados e informações através da análise do mercado e/ou de seus clientes, afetando o modo como as empresas operam e seu processo de desenvolvimento dos produtos (BEUREN; ORO, 2014).

É possível observar que o mercado competitivo também é um cenário de relação interorganizacional, onde neste contexto, uma empresa interage diretamente ou indiretamente com a outra através da competição ou alianças para desenvolver ou compartilhar diferenciais que trarão melhor visão de mercado para as mesmas, além de clientes, e outros benefícios que serão importantes para garantir sua prosperidade e manutenção no mercado (VERSCHOORE; BALESTRIN, 2008). Outro fator que deve se ater neste tipo de relação é a flexibilidade, ou seja, a capacidade de inovar no própria organização e assim disseminar na rede, conforme aponta Amato Neto (2000).

Outro tipo de relação interorganizacional são as parcerias entre universidades e as empresas, porém, segundo Calmanovici (2011), um dos maiores problemas enfrentados pelas empresas no Brasil, é a falta de investimentos em descobertas e avanços tecnológicos. Constatou-se que a maior parte dos investimentos realizados pelas indústrias, foi feito através de compra de maquinários mais modernos para melhorar, e/ou aumentar a produtividade. Porém, houve pouco investimento em pesquisa para o desenvolvimento de novas descobertas tecnológicas. Para solucionar este problema, é necessário que haja maior interação, investimentos e parcerias entre as empresas e as universidades, onde ambos trabalhando em 
conjunto poderão desenvolver e exportar novos avanços tecnológicos (CALMANOVICI, 2011).

Para tanto, uma boa estrutura de Governança interna dentro das pequenas empresas pode gerar diversos benefícios, como melhoria da comunicação entre funcionários, melhoria na qualidade e prestação de serviços, melhor desenvolvimento e padronização na qualidade de seus produtos, além de gerar inovação. Empresas que adotem uma boa prática relacionada à Governança Corporativa tendem trabalhar de forma mais organizada e com menos ruídos, desse modo, é possível organizar melhor a empresas e observar em quais pontos as mesmas podem melhorar, quais produtos podem ser desenvolvidos para gerar inovação e atrair mais clientes, trazendo maiores possibilidade para o comerciante manter uma posição sustentável no mercado (JARDIM; SAES; MESQUITA, 2013).

\section{Metodologia}

Optou-se por trabalhar com uma pesquisa qualitativa de caráter descritivo e exploratório. A pesquisa qualitativa tem como principal característica considerar as interpretações, opiniões e perspectivas dos indivíduos entrevistados que estão envolvidos na pesquisa (GOMES, et al., 2011). Ela permite mostrar a representatividade e as diferentes opiniões presentes nos grupos responsáveis por participar da pesquisa (MINAYO; ASSIS; SOUZA, 2006). Segundo MINAYO (2001), a pesquisa qualitativa se preocupa em responder questões sociais, que não podem ser respondidas pelas pesquisas quantitativas, pois trabalha com valores, opiniões e outros fatores que não podem ser mensurados através de questões objetivas. Dentro de uma pesquisa qualitativa de caráter descritivo e exploratório, é importante que o pesquisador esteja aberto e atento para observar possíveis descobertas, mesmo que haja um roteiro pré-estabelecido (GODOY, 1995).

A pesquisa foi realizada em restaurantes no centro histórico de uma cidade do interior de Minas Gerais. Utilizou-se o critério de acessibilidade para definir os restaurantes que foram estudados, por estarem situados em uma região altamente demanda por turistas, estudantes, funcionários de empresas locais e comunidade.

Foram entrevistados os proprietários ou os responsáveis por gerir e tomar as decisões no restaurante, para que desse modo, seja possível obter informações e conhecimentos mais eficazes e amplos através das perguntas contidas no roteiro de entrevista que permitirão compreender as relações interorganizacionais e a competitividade entre os restaurantes. Com o intuito de garantir o anonimato dos entrevistados e facilitar a compreensão dos dados apresentados, definiu-se nomes fictícios para os estabelecimentos e para os indivíduos participantes, sendo eles denominados: restaurante A e sujeito Alfa; restaurante B e sujeito Beta; restaurante C e sujeito Celta; restaurante D e sujeito Delta 1 e Delta 2. No Centro Histórico da respectiva cidade existem 7 estabelecimentos comerciais que atuam somente como restaurantes, sendo que somente 3 destes pontos comerciais não puderam participar devido a alguns empecilhos ou por não estarem dispostos a realizarem a entrevista.

A pesquisa foi desenvolvida através de entrevistas com o auxílio de um roteiro semiestruturado. De acordo com Muylaert et al. (2014), as entrevistas com roteiros semiestruturados, visam a profundidade de elementos específicos de determinado contexto situacional, incentivando o entrevistado a contar fatos e acontecimentos significativos. Nesse contexto, é muito importante que o entrevistador não julgue as afirmações dos informantes como certas ou erradas, pois estas representam a verdade sobre um ponto de vista ao qual o 
entrevistado estava inserido, podendo ser analisadas de diferentes formas após sua captação e transcrição dos dados. Outro fator mencionado, está relacionado a conduta do entrevistador, devendo o mesmo explicar, o contexto a ser investigado (MUYLAERT, et al. 2014). Dentro deste contexto, as entrevistas foram realizadas entre 13 de setembro de 2018 à 20 de setembro de 2018

Segundo Mozzato e Grzybovski (2011) na área de pesquisa científica da administração, existe um grande interesse pela análise de conteúdo como técnica para analisar dados, sendo destaque entre os métodos qualitativos devido ao aumento da exigência na qualidade das pesquisas. A análise de conteúdo é utilizada como meio de interpretar e converter os dados brutos obtidos através das pesquisas, sendo estas informações, construídas a base de técnicas que analisam a comunicação, para apresentar maiores informações dentro da leitura dos dados. Portanto, a técnica de análise de conteúdos apura os dados coletados em três etapas: a) a préanálise é a etapa que tem como objetivo tornar o material em algo operacional, estruturando as ideias iniciais através da leitura, escolha dos documentos, desenvolvimentos das hipóteses e objetivos, e por fim, a elaboração dos indicadores; b) consiste em analisar o material através de suas categorias, onde serão analisadas e definidas as categorias, para viabilizar a construção analítica através dos materiais textuais coletados. Desse modo, é possível fazer um estudo mais profundo através das hipóteses e dos referenciais teóricos; c) consiste em tratar os dados analisados e fazer as interpretações dos mesmos, condensando e destacando as informações por meio da interpretação e da análise crítica.

\section{Apresentação e Análise dos Resultados \\ 4.1 Apresentação}

Restaurante A

A entrevista no restaurante A se deu dentro de seu próprio estabelecimento e o entrevistado foi o próprio fundador e proprietário do restaurante. $\mathrm{O}$ empreendimento foi inaugurando em 1999, e a razão pela fundação do mesmo foi que o empreendedor viu a necessidade de criação de um local que oferecesse uma comida tipicamente mineira em sua cidade. O proprietário conta que a maior dificuldade na criação do empreendimento se deu pela adaptação, devido ao fato do mesmo não possuir experiência em estabelecimentos deste ramo, mas que conseguiu superar essas dificuldades através do trabalho e da observação das necessidades dos clientes, e com o passar do tempo conseguiu ir alinhando o empreendimento de acordo com suas diretrizes.

O sujeito Alfa vê a concorrência como algo saudável e percebe que existem benefícios em se ter concorrentes, pois demanda que os comerciantes melhorem cada vez mais seus produtos e a qualidade em seus serviços. O mesmo também compreende que para se manter à frente da concorrência, é necessário que o estabelecimento não se acomode e analise as necessidades de seus clientes, oferecendo produtos que os atendam, de modo que se ajustem de acordo com as demandas do mercado. Segundo o proprietário, seu grande objetivo não é ficar à frente de seus concorrentes, mas em um nível competitivo que satisfaça seus consumidores.

Segundo o mesmo, para melhorar o turismo na região, é necessário que haja um prefeito mais atuante e um departamento de turismo mais participativo, sendo necessário que tenha um secretário de turismo mais experiente. Essa estrutura em conjunto, poderia trabalhar para desenvolver o turismo na região através da criação e elaboração de planejamentos mais efetivos, 
de modo a incentivar e influenciar a vinda de turistas para a localidade, com o intuito de divulgar melhor a cidade e aquecer o comércio local, não somente voltado para essa prática, mas todos aqueles que possam se beneficiar da vinda dos mesmos, melhorando a economia da região.

Atualmente, o empresário vê que as maiores dificuldades em se manter um estabelecimento em sua região se dá não somente em torno da crise financeira brasileira, mas também a paralisação das atividades de uma grande empresa atuante em sua região, onde haviam vários funcionários da mesma almoçando em seu estabelecimento e atualmente boa parte de seu fluxo caiu em razão deste acontecimento. Porém, ele não vê que isso o impacta em sua capacidade de competir com outros estabelecimentos da região, pois os mesmos também sofreram esses impactos.

O sujeito Alfa relatou que atualmente seu restaurante não está inserido em nem um tipo de parceria econômica, e o que possui é um desconto para estudantes da Universidade estabelecida na região, mas o mesmo estaria interessado em ingressar em algum tipo de parceria, a fim de conseguir melhores fornecedores e preços. De acordo com a visão do empreendedor, a Universidade local pode influenciar no desenvolvimento comercial da cidade, desde que haja apoio mútuo entre a Universidade e a prefeitura, pois, a mesma é um campo rico em ideias e ferramentas, e em conjunto com os responsáveis por gerir a cidade, seria possível criar ferramentas, estruturas e atividades para envolver todo o comércio.

Seu estabelecimento possui como meio de divulgação o site da empresa, e sites de busca como Google e TripAdivisor, considerando que isso impacta no número de turistas que frequentam seu estabelecimento.

\section{Restaurante B}

A entrevista com o proprietário do restaurante B se deu dentro do próprio restaurante após o encerramento das atividades do mesmo. O restaurante foi inaugurado em 2018, e sua maior dificuldade foi à questão financeira, devido ao encerramento das atividades de uma grande empresa que atuava na região, e acabou por enfraquecer o comércio local. O mesmo conta que sua forma de superar os obstáculos enfrentados foi através da criatividade e muito trabalho.

O sujeito Beta coloca como seus principais diferenciais o preço, considerado pelo mesmo como um dos melhores da cidade, e a utilização de temperos caseiros para confeccionar seus alimentos, não utilizando produtos industriais, inclusive a maior parte da salada utilizada é orgânica, vindo da própria horta do dono do estabelecimento.

O sujeito Beta vê a concorrência de forma benéfica, livre e sincera, fazendo o empreendedor criar mais e ter mais ideias para modificar seus produtos, trazendo mais diversidade para o consumidor, onde o mesmo é quem acaba se beneficiando dessa disputa comercial. Dessa forma, ele acredita que é possível se manter à frente de seus concorrentes sem dificuldade alguma, sendo consolidada através da utilização de produtos orgânicos e não utilização de produtos industrializados.

Segundo Beta, a maior dificuldade em se manter um estabelecimento comercial atualmente são os impostos, considerando o governo como sócio do empreendimento devido as altas taxas tributárias cobradas, colocando-os como sócios quase majoritários em decorrência deste fato, o proprietário defende o imposto único como meio de diminuir essas taxas, que atualmente reduzem e muito sua margem de lucro. Porém, o proprietário não vê o problema dos impostos como algo que influencia em sua capacidade de competir, pois não há outro 
restaurante utilizando sua mesma estratégia de mercado. De acordo com Beta, para que os restaurantes possam prosperar ainda mais, é necessário que se reduzam as cargas tributárias.

De acordo com a visão do empreendedor, o que falta para melhorar o desenvolvimento do turismo na região é o interesse político, onde é necessário um secretário de turismo com maior conhecimento técnico, pois atualmente o indivíduo que ocupa o cargo não possui as qualificações necessárias para exercer tal função, sendo fundamental um profissional formado em turismo com conhecimento e experiência na área.

Atualmente o restaurante $\mathrm{B}$ está inserido em parcerias com fornecedores, mas não possui nenhuma parceria econômica com outros estabelecimentos, mas têm interesse de se inserir em uma parceria para redução de custos.

Segundo o sujeito Beta, a universidade pode interferir de forma positiva no comércio local devido ao consumo dos estudantes, o mesmo também acredita que a universidade pode desenvolver ferramentas para auxiliar o comércio, pois os proprietários possuem o conhecimento prático, porém, em algumas situações não possuem as ferramentas teóricas. Uma parceria entre ambos poderia gerar uma troca de conhecimento mútuo onde um aprenderia com o outro.

Seu estabelecimento possui como meio de divulgação a página no Facebook, panfletos, anúncios em rádio e jornal. Beta vê que quanto maior e melhor for à divulgação, melhor será a visibilidade do estabelecimento, colocando a propaganda como a alma do negócio, considerando a divulgação como um fator que interfere diretamente no número de turistas que frequentam seu estabelecimento.

\section{Restaurante $C$}

A entrevista no restaurante $\mathrm{C}$ ocorreu dentro do próprio estabelecimento antes das atividades do local serem iniciadas. O estabelecimento foi inaugurado em 2004, e a ideia de se inaugurar este estabelecimento surgiu de uma oferta feita para o irmão de Celta, que repassou a proposta para ela, que aceitou a oferta devido ao desafio e por representar algo novo para a mesma. Suas maiores dificuldades em inaugurar o restaurante se deram por conta da falta de experiência no ramo e a falta de mão-de-obra. A mesma conta que superou essas dificuldades com persistência, foco e determinação, onde se sentiu desafiada por se tratar de algo novo e à medida que as dificuldades foram surgindo, superando-as com muita persistência.

Celta coloca como seus principais diferenciais o ponto do estabelecimento, localizado de forma estratégica e sua abordagem direta com o cliente no dia a dia, vendo a concorrência como algo muito positivo, de modo que o comerciante quando se sente ameaçado irá tomar decisões para melhorar seu empreendimento, tirando-o de sua zona de conforto, considerando que só há benefícios em se ter concorrentes, pois os proprietários tendem a melhorar sua qualidade na prestação de serviço e seus produtos. Outro ponto importante relatado foi à importância em se ter variedades de comerciantes para atrair os clientes para aquela localidade, devido à quantidade de opções que os farão retornarem para aquele local, e em muitos casos, consumindo os serviços de vários pontos comerciais daquela mesma região.

O sujeito Celta acredita que é possível se manter à frente de seus concorrentes, mas o comerciante deve estar muito atento ao mercado, as novidades que surgem em prol do mesmo e aos novos estabelecimentos, que tendem a vir com ideias e novos produtos, portanto, o proprietário deve sempre analisar o mercado e estar pronto para lançar novos produtos e serviços em seu estabelecimento. A mesma também relata que é importante estar atento a 
realidade econômica da cidade, pois viu em seu tempo de atuação muitos comércios fechando e abrindo, focando em um público que não há na cidade, portanto, ela está atenta ao seu mercado e foca em seu público, trabalhando para melhorar sua qualidade e serviços, colocando o atendimento, a limpeza e a qualidade do produto como os fatores mais importantes para atrair os clientes.

Celta acredita que para melhorar o turismo na região é necessária uma melhor administração, pois considera que os comerciantes estão a um bom tempo abandonados em relação aos programas para atrair e desenvolver melhor o turismo. Para ela, é necessário melhorar a divulgação e valorizar mais os pontos turísticos da cidade, além de uma atenção à limpeza da cidade após os eventos, considerando que seja necessário um cuidado maior com a higiene da cidade, pois isso pode afetar a percepção que os turistas têm do local.

As maiores dificuldades em se manter um estabelecimento comercial atualmente são a mão de obra e as altas taxas de impostos. Outro ponto relatado foi a falta de investimento de infraestrutura na cidade, de modo a criar um comércio mais sustentável. Atualmente, o seu comércio não está inserido em nenhum tipo de parceria econômica a fim de conseguir melhores preços, mas a mesma estaria disposta a entrar em uma parceria para adquirir melhores preços e benefícios para todos que participarem da rede.

A visão da proprietária em relação à universidade é que a mesma é uma parceira do comércio e desenvolvedora de ferramentas e técnicas para melhoraria dos estabelecimentos, entretanto, questiona a atuação da universidade, onde o local está muito fechado e isolado das atividades da cidade, causando distanciamento entre os comerciantes e a universidade.

$\mathrm{O}$ restaurante $\mathrm{C}$ não possui meios de divulgação do restaurante, e acredita que essas ferramentas impactam na quantidade de turistas que frequentam o local, mas o que a fez afastar dessa área foram os altos preços cobrados para desenvolverem as divulgações.

\section{Restaurante D}

A entrevista no restaurante $\mathrm{D}$ ocorreu dentro do próprio estabelecimento comercial após o encerramento de suas atividades. O estabelecimento foi inaugurado em 1995, e a ideia surgiu através de uma das sócias que vinha trabalhar na cidade, até que um ponto comercial ficou à venda e a mesma entrou em contato com sua futura sócia para montarem o restaurante. Ambas não tiveram muitas dificuldades em se estabelecer, pois a família de uma das sócias já trabalhava com este tipo de empreendimento, e o processo de aprendizado se deu de forma natural através do estabelecimento de metas e do trabalho. Ambas atuam à frente das atividades do comércio junto aos funcionários em qualquer segmento da empresa, caso seja necessário.

Delta 1 e Delta 2 veem a concorrência como algo benéfico, tanto pela variedade de opções quanto para a cidade de modo em geral, considerando seus concorrentes como parceiros, considerando que quando se trabalha bem, não há porque temer os concorrentes. As proprietárias não têm como objetivo serem líderes de mercado, e identificam que o movimento é dividido entre todos os estabelecimentos. Sua estratégia para se manterem competitivas frente aos seus concorrentes é desempenhando da melhor forma suas atividades.

Em relação ao turismo, ambas veem que para melhorar esse ponto na região, é necessário que haja mais união entre os comerciantes e a prefeitura, além dos problemas relacionados a demora que se tem em realizar as reformas dos pontos turísticos, a falta de divulgação dos eventos realizados na cidade e a falta de um calendário de eventos para serem distribuídos não somente para os turistas, como também para os comerciantes de modo que eles 
possam se preparar para atender melhor seus clientes. Mas, ambas mencionam que através dos cortes nas verbas, algumas atividades deixaram de ocorrer na cidade e isso prejudica os movimentos culturais e o número de pessoas que visitam a mesma.

Para Delta1 e Delta2, as maiores dificuldades em se manter um estabelecimento comercial atualmente são os impostos, que reduzem bastante a arrecadação do estabelecimento e consideram a crise econômica também como segundo responsável por impactar em sua arrecadação. O estabelecimento não está inserido em nem um tipo de parceria para reduzir esses impactos, mas as sócias estão dispostas a se inserir em uma parceria caso atendam suas possibilidades e necessidades.

As respondentes acreditam que a universidade pode sim impactar na gestão do comércio local através de palestras, minicursos e parcerias como estágio, vendo como muito importante a ampliação da mesma através da expansão dos números de cursos disponíveis na cidade. Desse modo, tanto a universidade, quanto os estudantes, poderão se beneficiar de possíveis parcerias onde um poderá contribuir com o outro de modo que todos aprendam, aliando o pensamento teórico ao prático.

Atualmente o estabelecimento possui como meio de divulgação os sites de busca: da prefeitura, Idas Brasil, cachoeiras e TripAdivisor. D1 e D2 consideram bastante importante os meios de divulgação e acreditam que isso impacta no número de turistas que frequentam seu estabelecimento pois as pessoas antes de programar uma viajem, tendem a pesquisar e planejar sua estadia através de pesquisas online, e consequentemente, um local que tenha um site e/ou que esteja inserido em algum sistema de busca online, aumentará suas possibilidades de receber turistas.

\subsection{Análise dos resultados}

Todas as entrevistas ocorreram dentro dos próprios estabelecimentos. Os sujeitos Alfa e Celta tiveram como maior dificuldade na criação do empreendimento a adaptação devido ao fato dos mesmos não possuírem experiência em gerir estabelecimentos deste ramo. Beta e Alfa apontam como principal dificuldade a questão financeira devido ao encerramento das atividades de uma grande empresa que atuava na região, e acabou por enfraquecer o comércio local, enquanto os sujeitos Delta 1 e Delta 2 não tiveram muitas dificuldades em se inserirem no mercado, pois a família de uma das sócias já trabalhava com este tipo de empreendimento. $\mathrm{O}$ sujeito Celta ainda acrescenta como dificuldade a falta de mão-de-obra. Com base nessas informações pode-se concluir que o maior problema identificado na dificuldade em se criar um restaurante foi à falta de experiência dos empreendedores quando criaram o estabelecimento.

Os restaurantes A, B, C e D conseguiram superar suas dificuldades através do trabalho. O sujeito Alfa acrescenta que conseguiu superar essas dificuldades através da observação das necessidades dos seus clientes, enquanto Beta complementa a criatividade como fator para superar suas dificuldades. A entrevistada Celta acrescenta que conseguiu superar suas dificuldades através da persistência, foco e determinação, enquanto o estabelecimento de Delta 1 e Delta 2 apontam que a superação dos desafios se deu também através do estabelecimento de metas. Através das informações contidas acima, é possível observar que todos os empreendimentos conseguiram superar suas dificuldades através do trabalho, porém, cada um dos entrevistados acrescenta pontos divergentes de como superaram esses desafios.

Todos os respondentes veem a concorrência como algo benéfico, argumentando que só há benefícios em se ter concorrentes, considerando este tipo de interação como saudável e 
benéfico, onde os donos dos estabelecimentos deveram sair de sua zona de conforto e trabalhar na criação de produtos diferentes como forma de se destacarem no mercado, desse modo, tanto o comércio, os clientes e a cidade acabam sendo beneficiados, onde aumentará a atratividade daquele local, e consequentemente, um número maior de pessoas frequentarão os comércios situados nesta região, gerando benefícios para todos.

Apesar de Alfa não ter como objetivo ser líder de mercado, considera que para uma empresa se manter à frente de seus concorrentes é necessário que o empreendedor não se acomode e analise as necessidades de seus clientes, se ajustando de acordo com as demandas do mercado. O sujeito Beta, não vê dificuldades em se manter à frente dos concorrentes, enquanto Celta aponta que para se manter à frente de seus concorrentes é necessário que o comerciante esteja atento ao mercado, as novidades que surgem em prol do mesmo e aos novos estabelecimentos, portanto o proprietário deve sempre analisar o mercado e estar pronto para lançar novos produtos e serviços em seu estabelecimento. Os sujeitos Delta 1 e Delta 2 veem seus concorrentes como parceiros, e para um estabelecimento se manter competitivo no mercado acreditam que o mesmo deve desempenhar suas atividades da melhor forma possível. Metade dos estabelecimentos que participaram da análise acreditam que é possível se manter a frente de seus concorrentes, apenas os proprietários dos restaurantes D e A não abordam a questão de se manterem a frente de seus concorrentes, colocando-os como parceiros comerciais.

Os sujeitos Alfa e Delta 1 e Delta 2 não têm como objetivo serem líderes de mercado com seus respectivos restaurantes buscam como meta se manterem em um nível competitivo diante da concorrência. Os restaurantes Beta e Celta acreditam que é possível se manter à frente de seus concorrentes, onde o sujeito Beta aponta como seu diferencial a utilização de produtos orgânicos, temperos caseiros e o baixo preço de suas refeições. A sujeita Celta coloca como seus diferenciais a localização estratégica de seu estabelecimento e a abordagem direta com seus consumidores no dia-a-dia, complementando que foca em seu público com o intuito de melhorar sua qualidade e serviço prestado ao mesmo, considerando como fatores mais importantes o atendimento, a limpeza e a qualidade de seus produtos.

Através dos dados contidos acima, é possível observar que metade dos estabelecimentos acreditam que é possível se manterem a frente de seus concorrentes, enquanto a outra metade não vê em seus objetivos serem líderes de mercado, apenas buscam manterem uma posição comercial sustentável. Porém, os restaurantes B e C utilizam estratégias diferentes para buscarem a liderança entre os comerciantes do mesmo ramo.

Segundo o sujeito Alfa, para melhorar o turismo na região, é necessário que haja um prefeito mais atuante na cidade, enquanto Beta, aponta como principal fator o interesse político. Para a respondente Celta, falta uma melhor administração da cidade em relação às atividades ligadas ao turismo, enquanto as sócias do restaurante $\mathrm{D}$ colocam que deve haver maior união entre os comerciantes e a prefeitura, de modo que o trabalho em conjunto possa desenvolver melhor a atividade do turismo na região.

Os restaurantes $\mathrm{B}$ e C acrescentam que é necessário que haja um secretário de turismo mais experiente e com maior conhecimento técnico. Todos os entrevistados também apontam como outro fator a falta de divulgação dos eventos e do patrimônio histórico da cidade. O sujeito Celta acrescenta que deve haver uma limpeza melhor da cidade após a realização dos eventos, Delta 1 e Delta 2, complementam que deve haver um calendário de eventos que seja distribuído 
tanto para os turistas, quanto para os comerciantes, de modo que os proprietários possam se preparar para atender melhor seus clientes.

No ponto que toca a melhoria do turismo na região segundo a visão dos comerciantes, ambos abordam pontos diferentes em relação ao que deve ser feito para melhorar o turismo nesta localidade, porém, metade dos entrevistados acrescentam que falta um secretário de turismo mais experiente e com maior conhecimento técnico. Mas todos os problemas estão ligados diretamente a administração e gestão pública da cidade por parte da prefeitura.

Em relação às dificuldades em se manter um estabelecimento comercial atualmente, os sujeitos Alfa e Beta, apontam a crise financeira brasileira como fator que influenciam nas dificuldades em se manter um estabelecimento comercial, e Alfa acrescenta também a paralisação das atividades de uma grande empresa que atuava na região também como outro fator. Os sujeitos Beta, Celta e Delta 1 e Delta 2 colocam as altas cargas tributárias como principal fator que contribui em sua dificuldade em manter um estabelecimento comercial atualmente. Beta, complementa que é a favor do imposto único como meio de diminuir as taxas tributárias, Celta acrescenta que a mão-de-obra e a falta de investimentos em infraestrutura da cidade também são fatores que influenciam na dificuldade em se manter um estabelecimento comercial atualmente.

Com base nos relatos dos empresários, metade dos entrevistados colocam a crise financeira como fator que influencia nas dificuldades em se manter um estabelecimento comercial atualmente, e a maioria apontou as altas cargas tributárias como outro fator.

Todos os entrevistados não colocam esses fatores citados acima como agentes que influenciam em sua capacidade de competir com outros estabelecimentos, pois todos os empreendimentos da região foram impactados em decorrência dos mesmos. O sujeito Beta, acrescenta que não há nenhum estabelecimento comercial que adote a mesma estratégia de mercado que ele utiliza, portanto, esses fatores não afetam sua capacidade de competir.

Todos os estabelecimentos comerciais que participaram da entrevistam têm interessem em ingressar em uma parceria econômica entre os comerciantes locais a fim de melhorar sua lucratividade e reduzir seus custos. Apenas o restaurante B possui parceria com fornecedores, o que pode ser entendido como um diferencial.

Todos os comerciantes concordam que a universidade pode interferir no desenvolvimento econômico da cidade considerando a instituição como local onde novas técnicas e ferramentas são desenvolvidas, e as mesmas em conjunto com o comércio, podem trazer desenvolvimento tanto para os comerciantes locais através da aplicação dos conhecimentos adquiridos, quanto os comerciantes podem contribuir com a universidade através da prática que os mesmo têm de gestão de seu comércio no dia-a-dia, aliando a teoria junto a prática.

Alfa complementa que para o desenvolvimento efetivo do comércio, é necessário que haja uma parceria entre a prefeitura e a universidade. A proprietária do restaurante $\mathrm{C}$ acrescenta que a universidade está muito fechada e isolada das atividades da cidade, gerando distanciamento entre os comerciantes e a universidade. As sócias do estabelecimento D colocam que a universidade pode impactar também no comércio local através de parcerias com os comerciantes por intermédio de estágios, palestras e minicursos. Portanto, é possível observar que a maior parte dos comerciantes acrescentou pontos diferentes em relação à forma de atuação da universidade como fonte de auxílio para os empreendimentos locais. 
Todos os respondentes colocam que os meios de divulgação podem impactar no número de turistas que frequentam seu estabelecimento, porém, apenas a respondente Celta, preferiu se afastar dos meios de divulgação devido aos altos preços cobrados para desenvolver seus anúncios. Os proprietários dos estabelecimentos A e D utilizam sites de busca como Google e TripAdivisor para postarem seus anúncios, mas somente o restaurante A possui seu próprio site. Beta utiliza como meios de divulgação de seu estabelecimento uma página no Facebook, panfletos, anúncios em rádio e jornal, complementado que a propaganda é a "alma do negócio", e quanto maior e melhor for a divulgação do estabelecimento, maior será o número de turistas que frequentaram o seu comércio. Pode-se constatar que a maior parte dos estabelecimentos utiliza alguma ferramenta online de divulgação, mostrando a importância da internet e o quanto ela influencia e impacta atualmente na lucratividade e divulgação dos estabelecimentos comerciais.

\section{Considerações finais}

De acordo com a pesquisa realizada, foi possível perceber que os gestores dos restaurantes não percebem os parceiros que já possuem e acabam não tentando buscar benefícios em torno dessa situação. Um ponto a ser destacado são os fornecedores, pois os gestores dos restaurantes podem ter fornecedores em comum, e acabam não realizando compras em conjunto com o intuito de reduzir seus custos ou buscarem um fornecedor que ofereça mais vantagens, por não analisarem quem participa da cadeia de compras.

Este trabalho teve como objetivo analisar as estratégias de diferenciação adotadas por um grupo de restaurantes do centro histórico de uma cidade do interior de Minas Gerais que tangem como as empresas veem a concorrência, como elas diferenciam seus produtos, suas opiniões a respeito da divulgação de seu estabelecimento, e as visões de melhorias que os mesmos acreditam que possam ocorrer na cidade para atrair um número maior de turistas. Para tanto, lançou-se mão de uma pesquisa qualitativa de caráter descritivo exploratório, por meio de entrevistas semiestruturadas com os gestores de tais restaurantes, e posteriormente foi feita a apresentação e análise dos resultados.

Os principais resultados apresentados foram que todos os entrevistados têm a percepção de que falta uma melhor gestão pública da cidade voltada para o turismo, porém, todos os comerciantes estão interessados em participar de uma parceria econômica com outros comerciantes com o intuito de garantirem melhores preços e benefícios em busca de uma diferenciação. Todos os empreendedores colocam a concorrência como algo benéfico, pois a mesma possibilita que eles saiam de sua zona de conforto e trabalhem para desenvolver novos produtos e/ou serviços, dessa forma, a localidade onde estão inseridos passa a ter uma gama maior de opções e desse modo, acaba atraindo um número maior de pessoas devido à variedade de opções. Outro fator é que metade dos entrevistados acreditam que possam estar à frente de seus concorrentes, enquanto a outra metade possui como foco se manterem competitivos, mas não pretendem serem líderes de mercado. Nota-se que a busca pela diferenciação é algo amplamente recorrente nas falas, mas os critérios são tomados por motivações distintas.

Pode-se destacar através dos relatos dos proprietários foram que metade dos entrevistados considera que uma das maiores dificuldades em se montar um restaurante foi a falta de experiência em empreendimentos deste ramo, e a maioria considerou como os principais fatores que influenciam na dificuldade em se manter um estabelecimento comercial atualmente são as altas cargas tributárias cobradas, além da paralisação das atividades de uma 
grande empresa que atuava na região. Outros pontos observados foram que todos os empreendedores classificaram as divulgações como algo importante para atrair um número maior de turistas para seu estabelecimento, e a maioria desenvolve seus meios de divulgação, principalmente, através da internet.

O estudo teve como principais limitações a quantidade de empreendimentos que só atuam como restaurantes na cidade, pois a maioria diversifica seus ramos de atuação, e o número de entrevistados que concordaram em realizar as entrevistas. Todavia, entende-se que o objetivo foi cumprido, sendo possível a descrição e análise dos contextos estudados. O presente estudo pode contribuir demonstrando quais são as estratégias de diferenciação dos empreendedores que atuam no ramo de restaurantes, e suas percepções do comércio, turismo, divulgação, maiores dificuldades em se manter um estabelecimento comercial, diferenciais relacionados aos seus produtos e /ou serviços, como os mesmos se comportam diante de seus concorrentes e suas percepções a respeito da universidade local. Ademais, o trabalho contribui para o campo de estudos que possui como objeto de análise as pequenas empresas, organizações fundamentais para a sociedade contemporânea. Nota-se que a pesquisa contribuiu com os sujeitos pesquisados, já que foi possível estabelecer diálogos construtivos entre pesquisados e pesquisador. Assume-se como compromisso de pesquisa, o retorno aos estabelecimentos para dar o feedback final do estudo.

Como agenda de pesquisa é possível observar ainda: alguns dos principais impactos que uma universidade pode causar no desenvolvimento do comércio local; o modo como uma rede empresarial pode ser construída entre os restaurantes locais, a fim de possibilitar novas oportunidades aos negócios; observar o impacto direto dos investimentos públicos e privados no turismo para o cotidiano dos negócios locais; além de avaliar aspectos relacionados a promoção e divulgação dos negócios, atentando-se para o impacto no público dos estabelecimentos da cidade.

\section{REFERÊNCIAS}

ALVIM, P. C. R. C. O papel da informação no processo de capacitação tecnológica das micro e pequenas empresas. Ci. Inf., Brasília, v. 27, n. 1, p. 28-35, jan./abr. 1998.

AMATO NETO, J. Redes de cooperação produtiva e cluster regional: oportunidades para pequenas e médias empresas. São Paulo: Atlas, 2000.

BILLIG, O. A. de O.; BORELLI, V. A.; DIAS, D. T. de A.; RECH J. Análise das estratégias competitivas do setor de gastronomia de Caxias do Sul. R. Intelig. Compet., São Paulo, v. 6, n. 1,p.1-24, jan./mar.2016.

CALMANOVICI, C. E. A inovação, a competitividade e a projeção mundial das empresas brasileiras. Rev. USP, São Paulo, n. 89, p. 190-203, maio 2011.

CONTO, S. M.; FEIL, A. A. A Necessidade das Relações Interorganizacionais Frente à Atual Estrutura de Mercado. NAVUS - Revista de Gestão e Tecnologia, Florianópolis, v. 7, n. 3, p. 34-45, jul./set. 2017.

CUNHA, C. L.; VOGT, M.; BIAVATTI, V. T. Contribuições do Trabalho de Conclusão de Curso e do Estágio Curricular para a Aprendizagem: percepção dos alunos dos cursos de Ciências Contábeis. Rev. Contabilidade Vista \& Revista, Belo Horizonte, v. 26, n. 1, p. 57- 78, jan./abr. 2015.

GARNELO, L. Avaliação por triangulação de métodos: abordagem de programas sociais: Minayo MCS, Assis SG, Souza ER, organizadoras. Cad. Saúde Pública, Rio de Janeiro, v. 22, n. 5, p. 1115-1117, maio 2006.

GODOY, A. S. Pesquisa qualitativa: tipos fundamentais. Rev. Administração de Empresas, São Paulo, v. 35, n. 3 , p. 20-29, jun. 1995.

GOMES, R. et al. A atenção básica à saúde do homem sob a ótica do usuário: um estudo qualitativo em três serviços do Rio de Janeiro. Ciênc. saúde coletiva, Rio de Janeiro, v. 16, n. 11, p. 4 4513-4521, nov. 2011. 
HAGUENAUER, L., FERRAZ, J. C., KUPFER, D. S. Competição e internacionalização na indústria brasileira. In: BAUMANN, R. (Org.). O Brasil e a Economia Global. Rio de Janeiro: Campus, 1996.

HITT, Michael Alford; HOSKISSON, Robert; IRELAND, Duane. Competitividade e Globalização. 7a ed. São Paulo: Cengage Learning, 2008.

JARDIM, G. F.; SAES, M. S. M.; MESQUITA, L. F. Estruturas de governança interna e a capacidade de inovação em pequenas firmas brasileiras de torrefação e moagem de café. Rev. Adm. (São Paulo), São Paulo, v. 48, n. 2 , p. 239-253, jun. 2013.

LARENTIS, Fabiano; ANTONELlO, Claudia Simone; SLONGO, Luiz Antonio. Cultura organizacional e marketing de relacionamento: uma perspectiva interorganizacional. Rev. bras. gest. neg., São Paulo, v. 20, n. 1, p. 37-56, jan./mar. 2018 .

LOMBARDI, M. S.; BRITO, E. P. Z. Desenvolvimento sustentável como fator de competitividade. In: XXXI Encontro da ANPAD, Rio de Janeiro, 22-26 set. 2007.

MACHADO-DA-SILVA, C. L.; COSER, C. Rede de relações interorganizacionais no campoorganizacional de Videira-SC. Revista de Administração Contemporânea, v. 10, n. 4, p 9-45, out./dez.2006.

MARIOTTO, F. L. O conceito de competitividade da empresa: uma análise crítica. Rev. Administração de Empresas, São Paulo, v. 31, n. 2, p. 37-52, abr./jun. 1991

MINAYO, Maria Cecília de Souza; DESLANDES, Suely Ferreira; NETO, Otávio Cruz; GOMES, Romeu. Pesquisa Social: teoria, método e criatividade. $21^{\mathrm{a}}$ ed. Petrópolis: Vozes, 2002. 80 p.

MOTTA, R. A busca da competitividade nas empresas. Rev. Administração de Empresas, São Paulo, v. 35, n. 2,p.12-16,mar./abr.1995

MOZZATO, A. R.; GRZYBOVSKI, D. Análise de conteúdo como técnica de análise dedados qualitativos no campo da Administração: potencial e desafios. Revista de Administração Contemporânea, v. 15, n. 4, p. 731747, 2011.

MUYLAERT, C. et al . Entrevistas narrativas: um importante recurso em pesquisa qualitativa. Revista da Escola de Enfermagem da USP, São Paulo, v. 48, n. 2, p. 184-189, dez. 2014.

NETO, R. S.; PIZZOLATO, N. D. Uma Metodologia para a Análise da Competitividade Sistêmica Empresarial. ABEPRO - Associação Brasileira de Engenharia de Produção.

OLIVEIRA, L. de. A Estratégia Organizacional na competitividade: um estudo teórico. REAd, v. 10, n. 4, jul./ago. 2004.

SEBRAE, Inteligência competitiva para pequenas empresas. 2016. Disponível em: $<$ http://www.sebrae.com.br/sites/PortalSebrae/artigos/inteligencia-competitiva-para pequenasempresas,c77836627a963410VgnVCM1000003b74010aRCRD>. Acesso em: 22 set. 2018.

VALENTIM, M. L. P. et al. O processo de inteligência competitiva em organizações. DataGramaZero, Rio de Janeiro, v.4, n.3, jun. 2003.

VERSCHOORE, Jorge Renato; BALESTRIN, Alsones. Fatores relevantes para o estabelecimento de redes de cooperação entre empresas do Rio Grande do Sul. Revista de Administração Contemporânea (RAC), Curitiba, v. 12, n. 4, p. 1043-1069, out./dez. 2008.

WEIL, K. E. PORTER, Competitive advantage, creating and sustaining superiorperformance. Rev. Administração de Empresa, São Paulo, v. 25, n. 2, p. 82-84, jun. 1985. 